\title{
Aphicidal Activity of Surfactants Produced by Bacillus atrophaeus L193
}

\author{
Miguel Rodríguez ${ }^{1,2}$, Ana Marín 1,2, Marta Torres ${ }^{1,2,3}$, Victoria Béjar ${ }^{1,2}$, Mercedes Campos $^{4}$ \\ and Inmaculada Sampedro ${ }^{1,2 *}$
}

' Department of Microbiology, Pharmacy Faculty, Microbial Exopolysaccharide Research Group, Granada, Spain, ${ }^{2}$ Biomedical Research Center (CIBM), Biotechnology Institute, Granada, Spain, ${ }^{3}$ Institute for Integrative Biology of the Cell (I2BC), CEA/CNRS/University of Paris-Sud, University Paris-Saclay, Gif-sur-Yvette, France, ${ }^{4}$ Department of Plant Protection, Estación Experimental del Zaidín, Spanish National Research Council, Granada, Spain

\section{OPEN ACCESS}

Edited by:

José E. Barboza-Corona, Universidad de Guanajuato, Mexico

Reviewed by:

Fauzia Yususf Hafeez, COMSATS Institute of Information Technology, Pakistan Varinia Lopez,

Instituto Tecnológico Superior de Irapuato, Mexico

*Correspondence: Inmaculada Sampedro isampedro@ugr.es

Specialty section:

This article was submitted to Microbiotechnology, Ecotoxicology and Bioremediation,

a section of the journal

Frontiers in Microbiology

Received: 31 July 2018 Accepted: 03 December 2018 Published: 18 December 2018

Citation:

Rodríguez M, Marín A, Torres M, Béjar V, Campos M and Sampedro (2018) Aphicidal Activity of Surfactants Produced by Bacillus atrophaeus L193.

Front. Microbiol. 9:3114. doi: 10.3389/fmicb.2018.03114
The biosurfactants produced by Bacillus atrophaeus L193 was examined by their use in the control of the aphid Rhopalosiphum padi in order to suggest a friendly alternative to chemical pesticides. A screening of different culture media demonstrated the highest biosurfactant production by L193 in TSB supplemented with colloidal chitin. Surfactants, which are produced in large quantities $(2.04 \mathrm{~g} / \mathrm{L})$, reduce surface tension to $33 \mathrm{mN} / \mathrm{m}$. Electrospray Q-TOFS MS analysis demonstrated that lipopeptides, such as surfactins, fengycins, bacillomycins and iturins, are the predominant metabolites present in biosurfactants produced by strain L193. Treatment with L193 surfactants led to an aphid mortality rate of $59.8 \%$ within $24 \mathrm{~h}$. Microscopy analysis showed that these compounds caused insect death by affecting cuticle membranes. An evaluation of aphid feeding activity also demonstrated that aphid feeding capacity is affected by treatment with surfactants. Moreover, microbial cultures of strain L193 and their supernatants also showed high levels of activity against $R$. padi, which is probably due to the presence of surfactants and hydrolytic enzymes such as proteases and glucanases. This study demonstrates that B. atrophaeus L193 is an effective treatment for plants affected by aphids.

\section{Keywords: Bacillus atrophaeus L193, biosurfactants, lipopeptides, aphids, insecticidal activity}

\section{INTRODUCTION}

Aphid species Rhopalosiphum padi affects several cereal crops, resulting in severe economic losses in agriculture. These hemiptera insects are considered to be some of the most abundant and economically important aphids affecting both winter and spring wheat crops. $R$. padi leads to plant decline and transmits different phytopathogenic viruses including the barley yellow dwarf virus (BYDV) which causes chlorosis, stunting and yield loss (Biurrun et al., 2010; Liu et al., 2014). It also promotes the growth of fungi, such as Cladosporium sp. and Alternaria sp. on leaf surfaces through the excretion of sugars, and decreases the rate of plant photosynthesis (Dhami et al., 2013).

Currently, this pest is managed through the application of chemical insecticides. However, this can lead to resistance and pollute subterranean water due to soil lixiviation. In recent years, many 
predatory insects, though highly inefficient in open fields, have been used to control this pest in greenhouse crops. The use of microorganisms as biocontrol agents, which are typically members of the genus Bacillus, is a safe and environmentally friendly alternative to chemical pesticides (Copping, 2004).

Various studies have analysed the efficiency of Bacillus thuringiensis in the control of chewing insects such as Lepidoptera, Diptera, and Coleoptera (Bravo et al., 2007; Sanahuja et al., 2011). Nevertheless, few published studies have examined the insecticidal activity of the genus Bacillus against sucking insects such as aphids. Thus, studying the potential of these microorganisms as biocontrol agents against aphids could be worthwhile and contribute to the development of environmentally friendly approaches in agriculture.

The objective of this study is to analyse the biopesticidal activity of Bacillus atrophaeus L193 against the aphid R. padi. Thus, the production and physicochemical characteristics of L193 biosurfactants, as well as their anti-aphid insecticidal activity under controlled conditions were studied. The effect of B. atrophaeus L193 surfactant treatment on the aphid membrane was evaluated using microscopy analysis and by studying aphid feeding. These tests were also carried out on $B$. atrophaeus cultures and cell-free supernatants. To the best of our knowledge, this is the first study to evaluate the anti-aphid insecticidal activity of B. atrophaeus.

\section{MATERIALS AND METHODS}

\section{Microorganism Isolation and Identification}

The strain used in this study was isolated from the Malahá salt works (Granada, Spain, 37 $06^{\prime} 11.9^{\prime \prime} \mathrm{N} \mathrm{3} 3^{\circ} 43^{\prime} 14.6^{\prime \prime W}$ ) after 200 bacteria isolated from several hypersaline environments were screened in order to find the best producers of biosurfactants with insecticidal potential. The methodology used in this screening was the drop collapsing test described by Youssef et al. (2004). The 16S rRNA gene of strain L193 was amplified by PCR and sequenced using universal bacterial primers (Lane, 1991) 16F_B27 (5'AGAGTTTGATCMTGGCTCAG-3') and 16R_B1488 (5'-CGGTTACCTTGTTAGGACTTCACC-3'). $16 \mathrm{~S}$ rRNA fragments obtained by PCR were cloned into the pGEM-T vector (Promega ${ }^{\circledR}$ ) and later transformed into Escherichia coli $\mathrm{DH} 5 \alpha$. Vector plasmids were purified with the aid of an Illustra GFX DNA kit (GE Healthcare ${ }^{\circledR}$ ) according to the manufacturer's instructions. Sequencing was carried out in an Illumina NextSeq ${ }^{\mathrm{TM}} 500$ system. The resulting sequences were analysed with the DNAstar Lasergene Seqman programme (Madison, WI, United States). The sequences were identified using the GenBank and EMBL databases (Altschul et al., 1990) and the EzTaxon-e programme (Yoon et al., 2017).

\section{Biosurfactant Production}

Biosurfactant production of L193 strain was tested in the following media: Luria Bertani (LB), LB supplemented with 1\% (w/v) colloidal chitin, tryptic soy broth (TSB), TSB supplemented with $1 \%(\mathrm{w} / \mathrm{v})$ colloidal chitin, Cooper supplemented with $1 \%$ $(\mathrm{w} / \mathrm{v})$ colloidal chitin, Cooper supplemented with $4 \%(\mathrm{w} / \mathrm{v})$ glucose and Cooper supplemented with $1 \%(\mathrm{w} / \mathrm{v})$ colloidal chitin and 4\% (w/v) glucose (Cooper et al., 1981). Colloidal chitin was obtained as described by Wu et al. (2009).

To determine biosurfactant production (Song et al., 2013), strain L193 was cultured in $100 \mathrm{~mL}$ of each medium as described above at $28^{\circ} \mathrm{C}$ for 7 days and $130 \mathrm{rpm}$ rotary shaking. The cultures were centrifuged at $13,000 \mathrm{rpm}$ for $20 \mathrm{~min}$, and the cell pellets were freeze-dried. The supernatants were subjected to acid extraction in order to obtain the lipopeptides within it. The supernatant lipopeptides were then freeze-dried, and the difference in yield between cell biomass and biosurfactant was calculated.

\section{Biosurfactant Detection in L193 Culture on TSB Chitin Medium}

In order to detect biosurfactant production on strain L193, the evolution of surface tension in the strain culture was evaluated during $24 \mathrm{~h}$. Additionally, the surfactant activity of the strain L193 culture was studied using the drop-collapsing test, the oil spreading test and the emulsification index. All tests were carried out in triplicate using $1 \%(\mathrm{v} / \mathrm{v})$ Triton X-100 and sterile water as positive and negative controls, respectively.

Surface tension was measured at $25^{\circ} \mathrm{C}$ during $24 \mathrm{~h}$ using the Wilhelmy plate method (Biswas et al., 2001) with the aid of a Kruss K11 tensiometer. Samples were taken every hour during $24 \mathrm{~h}$ from a culture of strain L193 in TSB supplemented with $1 \%(\mathrm{w} / \mathrm{v})$ colloidal chitin. They were then centrifuged to obtain cell-free supernatants. Three replicates were measured per each sample.

The drop-collapsing test (Youssef et al., 2004) was performed in 96-well micro-titter plates by adding $2 \mu \mathrm{L}$ mineral oil to each well. After $1 \mathrm{~h}$ at room temperature to allow the stabilisation of the oil drops, $5 \mu \mathrm{L}$ of L193 supernatant were deposited on the mineral oil drop, and the shape of the drop was analysed by visual inspection after $1 \mathrm{~min}$. The reduction in surface tension caused by the presence of biosurfactant in the supernatant produced a flattened oil drop, while a round oil drop was produced in the absence of the biosurfactant.

For the oil-spreading test (Morikawa et al., 2000), $15 \mu \mathrm{L}$ crude oil were deposited on the surface of a 150-mm diameter Petri dish containing $40 \mathrm{~mL}$ destilled water. $10 \mu \mathrm{L}$ of the biosurfactant were then carefully deposited in the centre of the dish, and the radius of the clearly formed circle was measured in order to calculate the area of oil displacement.

The emulsification index (Cooper and Goldenberg, 1987) of the culture supernatants and the purified biosurfactant were determined in haemolysis tubes by mixing $4 \mathrm{~mL}$ of diferent hydrocarbons (such as almond oil, isopropyl mirystate and mineral oil) with an equal volume of cell-free supernatant or biosurfactant. After vortexing at maximum speed for $5 \mathrm{~min}$, the mixtures were left to stabilise at room temperature for $24 \mathrm{~h}$. The emulsification index $\left(\mathrm{E}_{24}\right)(\%)$ was expressed as the height of the emulsified fraction in relation to the total height of the mixture. 


\section{Determination of Hydrolytic Enzyme Production}

In order to quantify hydrolytic activity, strain L193 was cultured in $100 \mathrm{~mL}$ TSB medium supplemented with $1 \%(\mathrm{w} / \mathrm{v})$ colloidal chitin at $28^{\circ} \mathrm{C}$ for 5 days in a shaking incubator at $130 \mathrm{rpm}$. To obtain cell-free supernatants, the cultures were centrifuged at 13,000 rpm for $20 \mathrm{~min}$. Protease, chitinase and amylase activities of the supernatants were tested in 6-mm-diameter wells done in TSB media in Petri dishes containing 50\% (v/v) skimmed milk, 1\% (w/v) colloidal chitin and 1\% (w/v) anhydrous starch, respectively (Barrow and Feltham, 1993). Each activity was tested using $100 \mu \mathrm{L}$ of the pure supernatant (100\% concentration) and the supernatant diluted in water at concentrations of $50 \%$ and $25 \%$. For the protease and chitinase determination, plates were incubated at $28^{\circ} \mathrm{C}$ for 10 days. The radius of the transparent halos around the wells was measured after 5 and 10 days of incubation. Amylase activity was measured after 5 days using a Lugol's solution (Barrow and Feltham, 1993). A transparent halo arround the wells indicated a positive result for amylase activity, while if the medium remained dark blue/black meant that starch was not hydrolysed, therefore reacting with iodine of the Lugol's solution and dyeing the medium.

\section{Genetic Identification of Biosurfactant}

Non-ribosomal peptide synthetase (NRPS) genes coding for biosurfactant production were detected by PCR using specific degenerated primers described in Table 1. PCR amplifications were achieved in $50 \mu \mathrm{L}$ mixtures containing PCR buffer, $2 \mathrm{mM}$ $\mathrm{MgCl}_{2}, 4 \mathrm{mM}$ of each primer, $5 \mathrm{U}$ Taq polymerase, $0.2 \mathrm{mM}$ of each dNTP and 80-100 ng of genomic DNA. Amplification conditions were as follows: $95^{\circ} \mathrm{C}$ for $5 \mathrm{~min}, 40$ cycles at $94^{\circ} \mathrm{C}$ for $1 \mathrm{~min}$, annealing temperature for $1 \mathrm{~min}$, extension at $72^{\circ} \mathrm{C}$ for $1 \mathrm{~min}$ and a final extension at $72^{\circ} \mathrm{C}$ for $10 \mathrm{~min}$. Annealing temperatures were $45^{\circ} \mathrm{C}, 43^{\circ} \mathrm{C}, 50^{\circ} \mathrm{C}$, and $53^{\circ} \mathrm{C}$ for $\mathrm{Af} 2 / \mathrm{Tf} 1$, As1//Ts2, BmyBF/BmyBR and ItuDF/ItuDR, respectively (Chung et al., 2008; Tapi et al., 2010; Mora et al., 2011). The amplification products were analysed by electrophoresis in a $2 \%(\mathrm{w} / \mathrm{v})$ agarose gel after staining with RedSafe ${ }^{\mathrm{TM}}$ (Intron).

\section{Physicochemical Characterisation of Biosurfactant}

The L193 purified biosurfactant was characterised as explained above using the oil-spreading test (Morikawa et al., 2000), the emulsification index (Cooper and Goldenberg, 1987) and by measuring surface tension reduction and critical micelle concentration (CMC) (Phale et al., 1995). Finally, the chemical composition of the surfactant was determined by ultra performance liquid chromatography time-of-flight mass spectrometry (UPLC-TOF MS).

To determine the CMC, the reduction in surface tension in a $0.2 \%(\mathrm{w} / \mathrm{v})$ surfactant solution and its serial dilutions were measured at $25^{\circ} \mathrm{C}$ using a Kruss $\mathrm{K} 11$ tensiometer. The CMC of the L193 biosurfactant corresponded to the highest dilution of the surfactant that produced the maximum reduction in surface tension.
The chemical composition of the biosurfactant was analysed by UPLC-TOF MS using an Acquity UPLC ${ }^{\circledR}$ BEH300 C4 column $(1.7 \mu \mathrm{m}, 2.1 \times 50 \mathrm{~mm})$. The mobile phase used was a mixture of acetonitrile and water buffered with a solution containing $0.1 \%$ $(\mathrm{v} / \mathrm{v})$ formic acid in water. Analysis conditions were as follows: $10 \mu \mathrm{L}$ of sample at $40^{\circ} \mathrm{C}$ and an analysis time of $12 \mathrm{~min}$.

Mass spectrometry analysis was carried out by positive electrospray ionisation (ESI+) using a MS Waters SynaptG2 device. The analysis was done under the following conditions: capillary $3 \mathrm{Kv}$, source temperature $100^{\circ} \mathrm{C}$, desolvation temperature $500^{\circ} \mathrm{C}$, cone gas flow $40 \mathrm{~L} / \mathrm{h}$, desolvation gas flow $800 \mathrm{~L} / \mathrm{h}$, mass interval of detection from 100 to $2,400 \mathrm{Da}$ and survey scan time $0.1 \mathrm{~s}$. The data obtained were processed with the aid of MassLynx ${ }^{\mathrm{TM}}$ software (Waters).

\section{Insecticidal Activity Bioassay}

In order to determine the insecticidal potential of strain L193, the bacterial culture, supernatant and purified biosurfactant were tested in vivo against $R$. padi aphids (Agrobio S.L.).

To obtain the different treatments, strain L193 was cultured in TSB medium supplemented with $1 \%(\mathrm{w} / \mathrm{v})$ colloidal chitin at $28^{\circ} \mathrm{C}$ in a shaking incubator at $130 \mathrm{rpm}$ for 5 days. The supernatant was obtained by centrifugation at 13,000 rpm for $20 \mathrm{~min}$ and was then filtred through a $0.22-\mu \mathrm{m}$ pore filtre. The biosurfactant was extracted from the $250 \mathrm{~mL}$ culture supernatant as described above and was dissolved in $250 \mathrm{~mL}$ of sterile water.

Imidacloprid (50 $\mu \mathrm{g} / \mathrm{mL}$ ) was used as positive control. As negative controls, sterile cell-free TSB medium with $1 \%(\mathrm{w} / \mathrm{v})$ colloidal chitin was used for comparison with the whole culture and the supernatant treatments, while sterile water was used for comparison with the biosurfactant treatment.

The experimental model consisted of sixty individually grown barley (Hordeum vulgare) seedlings per treatment and control. Plants were grown in 0.2 pots filled with artificial soil at $23^{\circ} \mathrm{C}$. Three-day barley seedlings (plant height: $6-7 \mathrm{~cm}$ ) were initially infested with three $3^{\text {rd }}$-instar $R$. padi aphids and grown for 7 days in a growth chamber at $25^{\circ} \mathrm{C}, 60 \%$ humidity and for a $16 \mathrm{~h}$ light/8 h dark photoperiod. To avoid aphid dispersion, each plant was covered with transparent plastic film.

The insecticidal experiment lasted 5 days after the 7 days of plant growth. The treatments and controls were sprayed $(0.5 \mathrm{~mL}$ per plant) on day 1 and 3 of the assay while ensuring that the whole aphid population and plant surface were covered with the spray solution. The dead and living aphids of each plant were counted daily.

Aphid mortality was calculated using Abbot's formula (Abbott, 1925), which compares living aphids in each treatment (At) with living aphids in each control (Ac):

$$
\operatorname{Mortality}(\%)=\left(1-\frac{A t}{A c}\right) \times 100 .
$$

\section{Determination of Aphid Feeding}

To test whether the treatments affected aphid feeding capacity, ten barley seedlings infested each with three $3^{\text {rd }}$-instar aphids were used for each treatment and control. The experiment 
TABLE 1 | PCR primers of lipopeptide biosynthesis genes in Bacillus atrophaeus L193.

\begin{tabular}{|c|c|c|c|c|c|}
\hline Lipopeptide & Gene & Primers & Primer sequences $\left(5^{\prime} \rightarrow 3^{\prime}\right)$ & PCR product size (bp) & Reference \\
\hline \multirow[t]{2}{*}{ Fengycin } & fenC & Af2 (F) & GAATAYMTCGGMCGTMTKGA & $443-455$ & Tapi et al., 2010 \\
\hline & & $\mathrm{Tf1}(\mathrm{R})$ & GCTIWADKGAATSBCCGCC & & \\
\hline \multirow[t]{2}{*}{ Surfactin } & sifA-A & As1 (F) & CGCGGMTACCGVATYGAGC & $419-431$ & Tapi et al., 2010 \\
\hline & & Ts2 (R) & ATBCCTITBTWDGAATGTCCGCC & & \\
\hline \multirow[t]{2}{*}{ Bacillomycin } & bmyB & $\mathrm{BmyB}(\mathrm{F})$ & GAATCCCGTTGTTCTCCAAA & 370 & Mora et al., 2011 \\
\hline & & BmyB (R) & GCGGGTATTGAATGCTTGTT & & \\
\hline \multirow[t]{2}{*}{ Iturin } & $i t u D$ & ItuD (F) & TTGAAYGTCAGYGCSCCTाT & 482 & Chung et al., 2008 \\
\hline & & ItuD (R) & TGCGMAAATAATGGSGTCGT & & \\
\hline
\end{tabular}

conditions were the same as described above, but in this case 90-mm diameter filtre paper discs were placed at the base of each plant stem to collect honeydew drops from the aphids (Kim and Jander, 2007).

In order to avoid contamination of the filtre paper disc by the soil, a Petri dish (with an opening for the stem) was placed between the filtre and the soil. Likewise, when the treatments and controls were sprayed on the seedlings, the filtre and dish were removed to avoid their contamination. Discs containing honeydew from the aphids were collected after $96 \mathrm{~h}$ and were immersed in a $0.1 \%(\mathrm{w} / \mathrm{v})$ ninhydrin solution in acetone. Discs were oven-dried at $65^{\circ} \mathrm{C}$ for $30 \mathrm{~min}$ and cut into strips. The purple/pink spots were extracted with $4 \mathrm{~mL}$ of $90 \%(\mathrm{v} / \mathrm{v})$ methanol by vortexing for $1 \mathrm{~h}$ at maximum speed. The tubes were then centrifuged at 5,000 rpm for $10 \mathrm{~min}$, and supernatant absorbance was measured at $500 \mathrm{~nm}$ using $90 \%$ (v/v) methanol as blank (Nisbet et al., 1994).

\section{Microscopy Analysis}

After the in vivo assay described above, dead aphids from plants treated with the bacterial culture or the biosurfactant, as well as water-control aphids, were collected in order to analyse the effect of treatments using optical, scanning electron and transmission electron microscopy. The samples were prepared as described by Kim et al. (2011). Briefly, for scanning electron microscopy analysis, aphid samples were fixed with $2 \%(\mathrm{v} / \mathrm{v})$ glutaraldehyde and $2 \%(\mathrm{v} / \mathrm{v})$ paraformaldehyde in $50 \mathrm{mM}$ cacodylate buffer at $\mathrm{pH} 7.4$ for $48 \mathrm{~h}$ at room temperature. After fixing, the samples were washed three times in the cacodylate buffer and dehydrated through 50, 70, 90, and $100 \%$ ethanol for $5 \mathrm{~min}$ in each stage. The samples were dried and examined with a scanning electron microscope. For transmission electron microscopy analyses, aphid samples were immersed in $2.5 \%(\mathrm{v} / \mathrm{v})$ glutaraldehyde in $0.1 \mathrm{M}$ PBS buffer at $\mathrm{pH} 7.4$ for $48 \mathrm{~h}$ at $4^{\circ} \mathrm{C}$. Following washing with the PBS buffer, the samples were immersed in a mixture of $2 \%$ osmium tetroxide and $3 \%(\mathrm{v} / \mathrm{v})$ ferrocyanide $(1: 1, \mathrm{v} / \mathrm{v})$ in the same buffer for $1 \mathrm{~h}$ at $4^{\circ} \mathrm{C}$. After a washing with the PBS buffer, the samples were dehydrated in a series of ethanol solutions and embedded in Epon 812. Ultrathin sections were mounted on Formvar-coated nickel grids (200 mesh) and stained with aqueous uranyl acetate and alkaline lead citrate for $5 \mathrm{~min}$. The samples were then examined with a transmission electron microscope.

\section{Statistical Analyses}

Data normality was checked using the Shapiro-Wilk test. Since the data did not follow a normal distribution pattern, even after natural logarithmic and Box-Cox transformation, KruskalWallis and Mood's median tests were used to determine whether the five treatments differed significantly $(p \leq 0.05)$ in terms of aphid mortality. The Mann-Whitney $\mathrm{U}$ test with the Bonferroni correction was then used for pairwise comparisons of the treatments.

\section{RESULTS}

\section{Microorganism Isolation and Identification}

The strain used in this study was isolated from a soil sample taken from the Malahá salt works (Granada) in the south-east of Spain. The $16 \mathrm{~S}$ rRNA gene sequence $(1,355 \mathrm{bp})$ indicated that the strain belongs to the genus Bacillus. It showed 16S rRNA gene-sequence similarity of $99.5 \%$ to its closest relative B. atrophaeus. The isolate was named B. atrophaeus L193.

\section{Biosurfactant Production}

Different culture media were screened in order to determine in which of these media the biosurfactant production was higher (Table 2). TSB supplemented with colloidal chitin, in which strain L193 produced $2.04 \mathrm{~g} / \mathrm{L}$ of biosurfactants, was selected and used as the culture medium to perform the subsequent experiments.

\section{Biosurfactant Detection in L193 Culture on TSB Chitin Medium}

The cell-free supernatant of strain L193 grown in TSB medium supplemented with $1 \%(\mathrm{w} / \mathrm{v})$ colloidal chitin produced a clear

TABLE 2 | Surfactant production by B. atrophaeus L193 in different culture media.

\begin{tabular}{lccccccc}
\hline & LB & LB chitin & TSB & $\begin{array}{c}\text { TSB } \\
\text { chitin }\end{array}$ & $\begin{array}{c}\text { Cooper } \\
\text { chitin }\end{array}$ & $\begin{array}{c}\text { Cooper } \\
\text { glucose }\end{array}$ & $\begin{array}{c}\text { Cooper } \\
\text { glucose } \\
\text { chitin }\end{array}$ \\
\hline $\begin{array}{l}\text { Surfactant } \\
\text { (mg/L) }\end{array}$ & 502.4 & 281.2 & 1620.8 & 2040.0 & 203.6 & 271.6 & 284.0 \\
$\begin{array}{l}\text { Biomass } \\
\text { (mg/L) }\end{array}$ & 1640 & 1424 & 1908 & 1840 & 1516 & 416 & 1450 \\
Yield & 0.31 & 0.20 & 0.85 & 1.11 & 0.13 & 0.65 & 0.20 \\
\hline
\end{tabular}




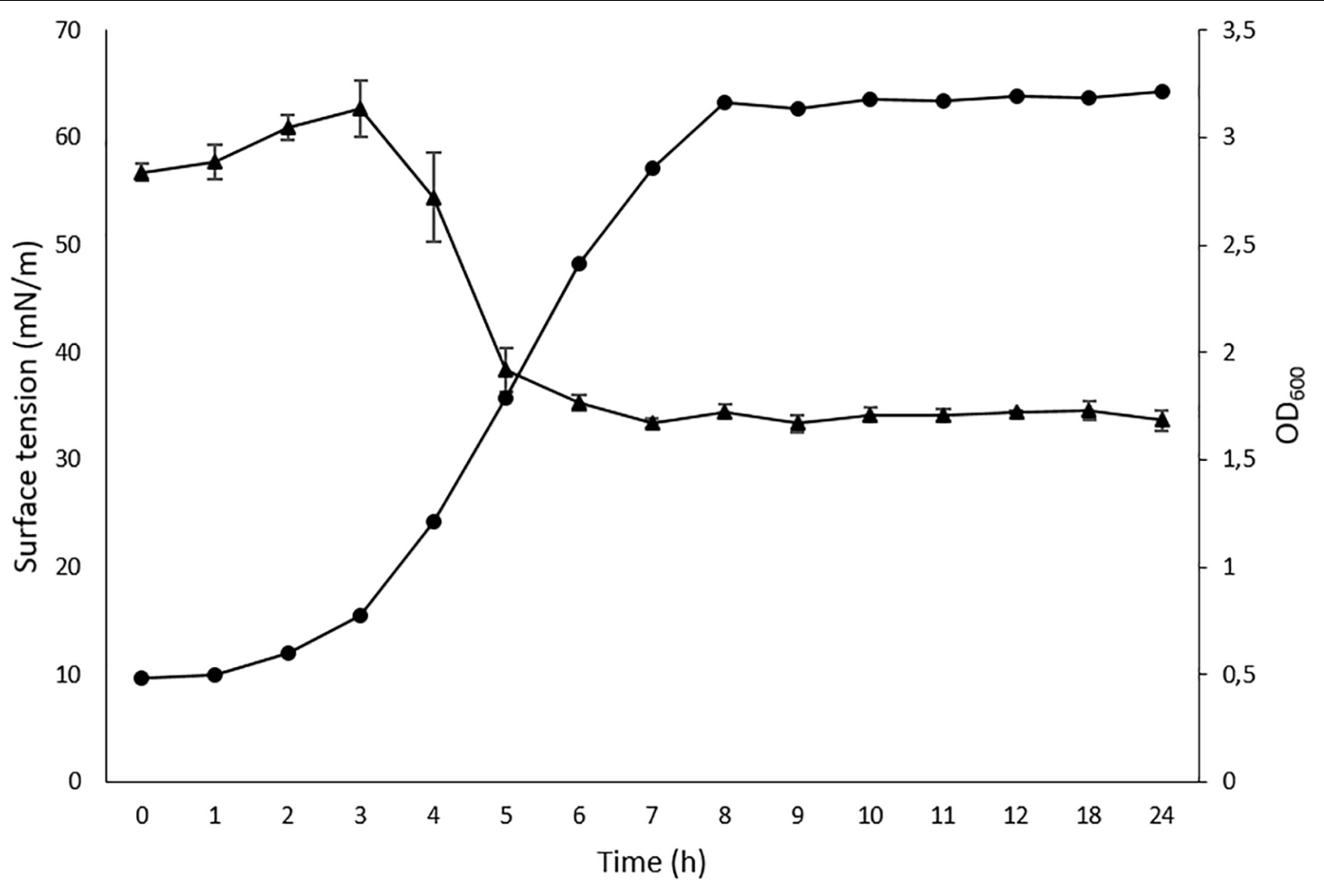

FIGURE 1 | Time-course cell density $(\mathbf{O})$ and surface tension $(\mathbf{\Delta})$ values for Bacillus atrophaeus L193. Data represent mean \pm standard deviation of the triplicates.

halo zone of $24.95 \mathrm{~cm}^{2}$ in the oil displacement test, while the drop-collapsing test was also positive (data not shown). The emulsification index $\left(\mathrm{E}_{24}\right)$ for cell-free supernatant activity against mineral oil, almond oil and isopropyl myristate was $8.08 \%$ $( \pm 1.24), 42.63 \%( \pm 2.63)$, and $3.73 \%( \pm 1.31)$, respectively. The reduction in surface tension reached a maximum $(33.0 \mathrm{mN} / \mathrm{m})$ after $4.5 \mathrm{~h}$ of incubation (Figure 1).

\section{Determination of Hydrolytic Enzyme Production}

In this study, we analysed the production of glucosidase enzymes (amylase and chitinase) and proteases (caseinase) by strain L193 in order to determine its potential insecticidal capacity. The undiluted L193 culture supernatants on 1\% (w/v) TSB chitincontaining media displayed enhanced amylase, chitinase and caseinase production (Table 3 ).

TABLE 3 | Amylase, chitinase and caseinase activities of B. atrophaeus L193 supernatants on TSB medium supplemented with $1 \%(\mathrm{w} / \mathrm{v})$ colloidal chitin.

\begin{tabular}{lccc}
\hline & Amylase $^{*}$ & Chitinase & Caseinase \\
\hline Supernatant (100\%) & 15 & 3 & 10 \\
Supernatant (50\%) & 14 & 2 & 7 \\
Supernatant (25\%) & 11 & 1 & 4
\end{tabular}

*Enzimatic activity was determined by measuring the hydrolysis halo (mm) produced in the different culture media.

\section{Genetic Characterisation of Biosurfactant}

Genomic analysis indicates that B. atrophaeus L193 contains nonribosomal lipopeptide synthetase gene clusters, which include genes involved in producing fengycin, surfactin, bacillomycin and iturin, such as fenC, srf A-A, bmy B and ituD (Supplementary Figure S1).

\section{Physicochemical Characterisation of Biosurfactant}

In order to analyse the efficiency of biosurfactants extracted from strain L193, critical micelle concentration (CMC) as well as emulsification and oil spreading (displacement) activity were measured. The value obtained for CMC was $9.38 \mathrm{mg} / \mathrm{L}$. The oil spreading test showed a displacement halo area of $33.87 \mathrm{~cm}^{2}$ for L193 relative to $55.42 \mathrm{~cm}^{2}$ for the positive control Triton X100 (Supplementary Figure S2). The emulsification index $\left(\mathrm{E}_{24}\right)$ for L193 biosurfactant activity against mineral oil, almond oil and isopropyl myristate was $51.53 \%( \pm 1.39), 46.87 \%( \pm 1.46)$, and $38.05 \%( \pm 11.21)$, respectively (Supplementary Table S1). These emulsification indices for the surfactant produced by L193 were slightly lower than those for the positive control Triton $\mathrm{X}-100$. Except with regard to almond oil, all the values for the biosurfactant were higher than those for the supernatant of L193 cultures. The emulsification index of water (negative control) for these compounds was 0\% (Supplementary Figure S3). 


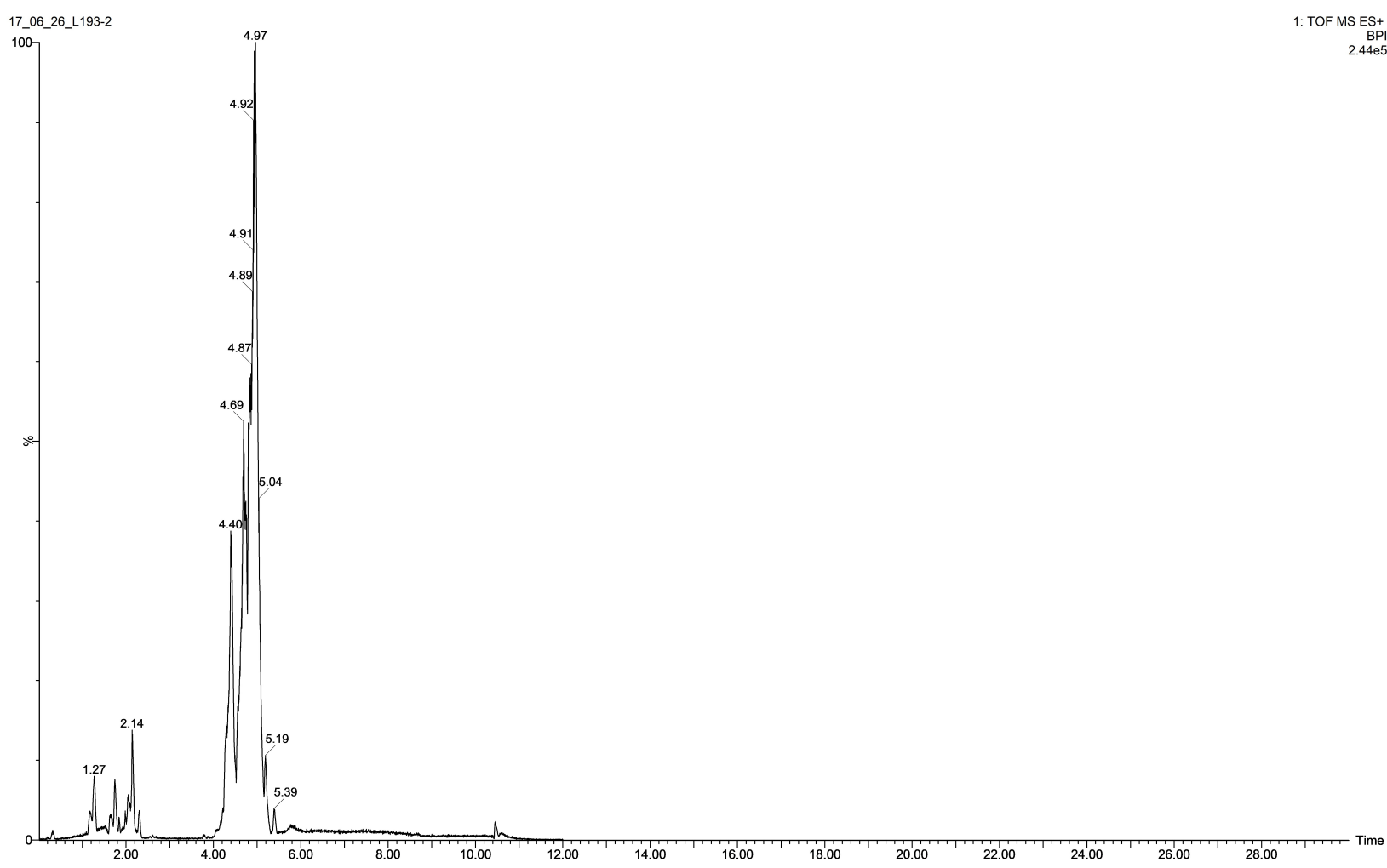

FIGURE 2 | TIC spectrum obtained from the surfactant of B. atrophaeus L193 cultured in TSB medium supplemented with 1\% (w/v) colloidal chitin.

Ultra-performance liquid chromatography time-of-flight mass spectrometry (UPLC-TOFS MS) was used to identify metabolites produced by the isolate tested. Figure 2 illustrates the total ion chromatogram (TIC) spectrum of the B. atrophaeus L193 culture extract.

The analyses show that strain L193 can produce various types of lipopeptides. Four known surfactins, with an acyl chain ranging from $\mathrm{C} 12$ to $\mathrm{C} 15$, as well as two known types of bacillomycin F (C15 and $\mathrm{C} 16)$ were detected. Iturin $\mathrm{A}$ and fengycin $\mathrm{B}$ peaks were also observed (Table 4). UPLC-TOF MS detected two predominant compounds: an $[\mathrm{M}+\mathrm{H}]$ peak at $\mathrm{m} / \mathrm{z} 1,057.5736$ for iturin $A$ with molecular formula $\mathrm{C}_{49} \mathrm{H}_{76} \mathrm{~N}_{12} \mathrm{O}_{14}$ and an $[\mathrm{M}+\mathrm{H}]$ peak

TABLE 4 | Lipopeptide production by B. atrophaeus L193 as detected by Q-TOF MS.

\begin{tabular}{lcrccc}
\hline Lipopeptide & $\begin{array}{c}\text { Fatty chain } \\
\text { length }\end{array}$ & {$[\mathbf{M}+\mathbf{H}]$} & $\begin{array}{c}\text { Retention } \\
\text { time (min) }\end{array}$ & Area (\%) & $\begin{array}{c}\text { Peak } \\
\text { intensity }\end{array}$ \\
\hline Iturin A & $\mathrm{C} 15$ & 1057.5736 & 1.27 & 2.00 & $1.95 \mathrm{e} 4$ \\
Bacillomycin F & $\mathrm{C} 15$ & 1071.5880 & 1.53 & 0.37 & $4.77 \mathrm{e} 3$ \\
& $\mathrm{C} 16$ & 1085.6064 & 1.74 & 1.18 & $1.86 \mathrm{e} 4$ \\
Fengycin B & $\mathrm{C} 15$ & 1477.8317 & 2.15 & 2.54 & $5.99 \mathrm{e} 3$ \\
Surfactin & $\mathrm{C} 12$ & 994.6420 & 4.21 & 0.05 & $9.92 \mathrm{e} 3$ \\
& $\mathrm{C} 13$ & 1008.6595 & 4.40 & 15.47 & $9.55 \mathrm{e} 4$ \\
& $\mathrm{C} 14$ & 1022.6754 & 4.69 & 2.31 & $1.29 \mathrm{e} 5$ \\
& $\mathrm{C} 15$ & 1036.6947 & 4.97 & 72.50 & $2.46 \mathrm{e} 5$
\end{tabular}

at $\mathrm{m} / \mathrm{z} \quad 1,036.6947$ for surfactin with molecular formula $\mathrm{C}_{53} \mathrm{H}_{93} \mathrm{~N}_{7} \mathrm{O}_{13}$ (Figures 3A,D, respectively). Also an $[\mathrm{M}+\mathrm{H}]$ peak at $\mathrm{m} / \mathrm{z}$ 1,085.6064, for bacillomycin $\mathrm{F}$ with a molecular formula $\mathrm{C}_{51} \mathrm{H}_{80} \mathrm{~N}_{12} \mathrm{O}_{14}$ and an $[\mathrm{M}+\mathrm{H}]$ peak at $\mathrm{m} / \mathrm{z}$ 1,477.8317 for fengycin $\mathrm{B}$, with a molecular formula $\mathrm{C}_{73} \mathrm{H}_{112} \mathrm{~N}_{12} \mathrm{O}_{20}$ (Figures 3B,C, respectively) were detected. No mass signals were assigned to other lipopeptides. This agrees with the results obtained by the PCR analysis (Supplementary Figure S1).

\section{Insecticidal Activity Bioassay}

In order to evaluate the aphicidal activity of B. atrophaeus L193, in vivo studies were conducted in barley plants infested with three $3^{\text {rd }}$-instar $R$. padi aphids, and treated or untreated with strain L193 culture, cell-free supernatant or purified extract. The results show high levels of activity against $R$. padi for all of the treatments. The differences between the treatments and control were, in all cases, highly significant $(p \leq 0.05)$. The highest mortality rate of aphids was obtained $24 \mathrm{~h}$ after the first treatment (Figure 4). Imidacloprid, a neonicotinoid commonly employed for aphid control, with $100 \%$ mortality after $24 \mathrm{~h}$, was used as positive control (data not shown in Figure 4).

Given the corrected mortality based on Abbot's formula, an enhanced insecticidal activity was observed in the biosurfactant (59.8\%) as compared to the culture (50.6\%) and the cell-free supernatant (47.7\%) of B. atrophaeus L193 (Supplementary Table S2). 
A

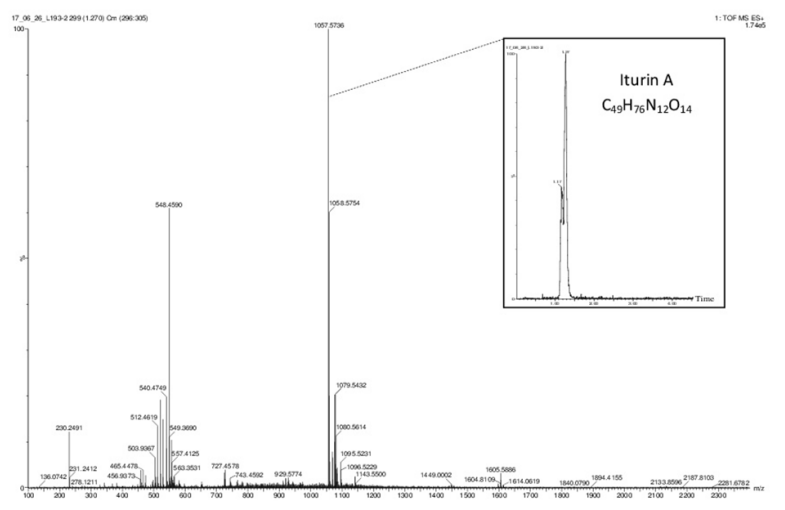

B

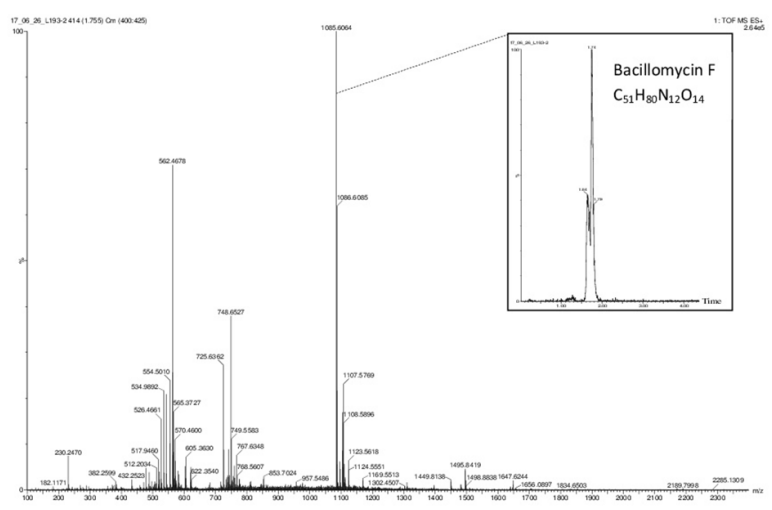

C

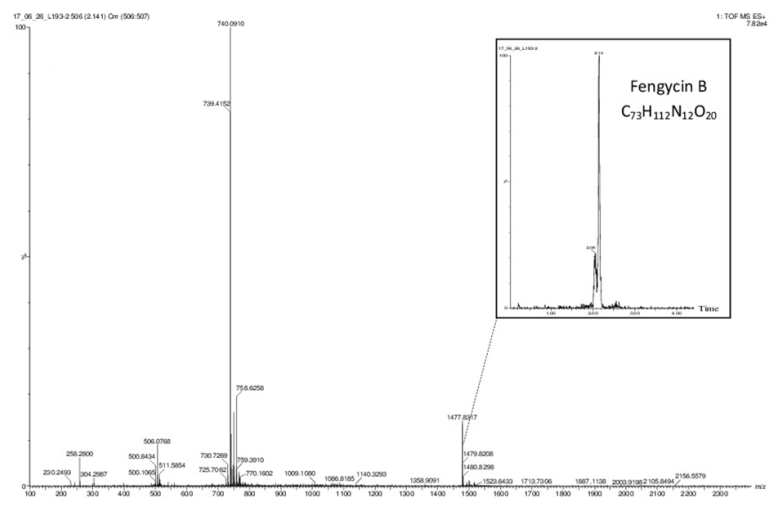

D

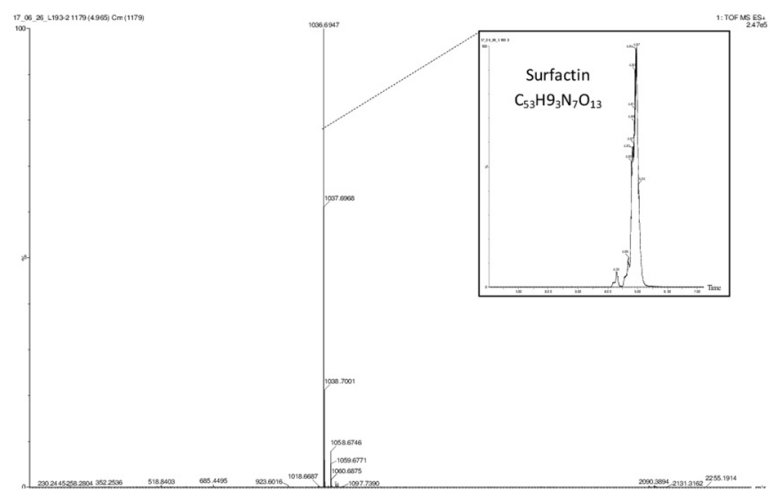

FIGURE 3 | Q-TOF MS spectra obtained from the surfactant produced by $B$. atrophaeus L193: protonated linear derivatives of the $[M+H]$ of iturin $A(\mathbf{A})$, bacillomycin $F(B)$, fengycin B (C), and surfactin (D).

\section{Determination of Aphid Feeding}

Aphid feeding capacity was evaluated by measuring the amount of honeydew excreted by the whole aphid population after $96 \mathrm{~h}$. The samples corresponding to the L193 culture and cell-free supernatant treatments showed a reduction of 38.5 and $42.9 \%$ in the honeydew excreted, respectively, as compared to controls. L193 surfactant treatment samples showed a reduction of $28.7 \%$ as compared to controls.

\section{Microscopy Analysis}

The signs of $R$. padi infection caused by topic treatment with $B$. atrophaeus L193 were observed by optical microscopy and are shown in Figure 5. Aphids exposed to L193 ceased to move, their bodies were dehydrated and their green colour darkened.

Scanning electron microscopy (SEM) and Transmission electron microscopy (TEM) data on aphids treated with TSB medium and the L193 culture or the biosurfactant produced by L193 are shown in Figure 6. SEM analysis of aphids treated with TSB medium alone showed an intact cuticle (Figure 6A), while clear evidence of damaged cuticle was detected in aphids treated with L193 culture and the biosurfactant (Figures 6B,C, respectively). TEM and optical microscopy confirmed that treatment with strain L193 affects the cuticular membrane of the aphids, with a $36.23 \%$ reduction in thickness in the case of the bacterial culture treatment (Figure 6E) and a 58.35\% reduction with the L193 surfactant treatment (Figure 6F). With regard to treatment with the biosurfactant, a clear change in cuticle structure was also observed.

With regard to treatment with the L193 culture, TEM micrographs also highlighted the presence of a bacterial cell monolayer firmly attached to the cuticle surface of aphids (Figure 6E), with bacterial cells sometimes appearing to cause the development of a pseudopod-like structure in the aphid cuticle (Supplementary Figure S4A). SEM micrographs showed cuticle concavity in the aphids (Supplementary Figure S4B).

\section{DISCUSSION}

The strain used in this study showed 16S rRNA gene-sequence similarity of $99.5 \%$ to its closest relative $B$. atrophaeus. The isolate was named B. atrophaeus L193.

Several studies have previously highlighted the potential of different Bacillus strains to act as biocontrol agents against insect pests. The effect of these bacteria has been tested in relation to a wide range of agronomically important pests including aphids (Dutton et al., 2003; Palma et al., 2014; Rashid et al., 2017). As 


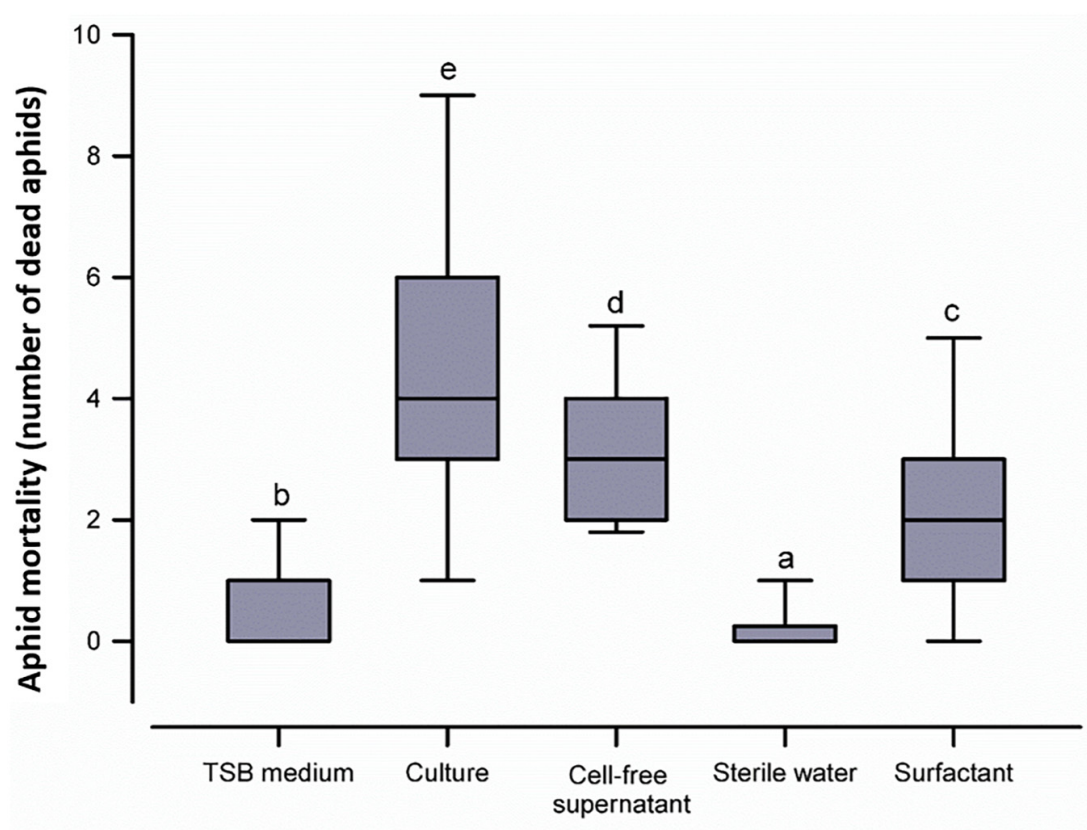

Treatments

FIGURE 4 | Box plot representing aphid mortality with the five treatments tested. The centre line of the box depicts the median, the edges of the box reflect the 25 th and 75th percentiles (interquartile range), and the whiskers depict the 10th and 90th percentiles. Different letters above the whiskers indicate significant differences $(p \leq 0.05)$ between treatments according to the Mann-Whitney $U$ test.
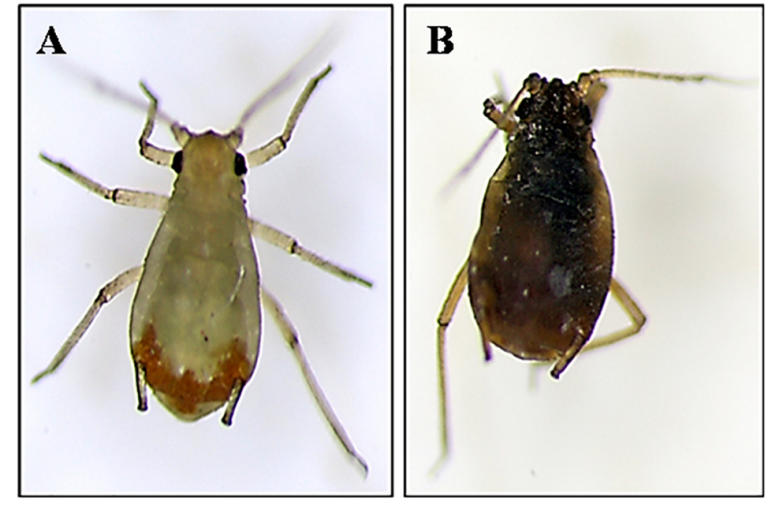

FIGURE 5 | Signs of infection in Rhopalosiphum padi caused by

B. atrophaeus L193 observed by stereo microscopy. (A) Treatment with water (control). (B) Treatment with L193 surfactant.

explained elsewhere, these insects are considered to be the most destructive agents affecting several crops and the agricultural economy (Leroy et al., 2011).

Most studies have analysed the biopesticidal activity of the genus Bacillus against the green peach aphid Myzus persicae, one of the most destructive pests, which causes huge crop loss (TorresQuintero et al., 2015). The most common Bacillus species tested against $M$. persicae is the entomopathogenic bacterium Bacillus thuringiensis (Torres-Quintero et al., 2015). This bacterium produces crystalline inclusions composed of insecticidal crystal proteins (ICP) and endotoxins. Although these ICPs and toxins are highly active against several orders of insects, various studies have shown low to moderate toxicity to aphids (Porcar et al., 2009). It would therefore be interesting to study the potential of other Bacillus species to act as biocontrol agents against these insects. To the best of our knowledge, this is the first study to analyse the anti-aphid insecticidal activity of $B$. atrophaeus, which we tested against Rhopalosiphum padi (L.) (Homoptera: Aphididae), one of the most abundant and economically important aphids in both winter and spring wheat crops.

Biosurfactant production by L193 was tested in different culture media. The data showed that the culture medium used in the growth of the microorganism can decisively influence biosurfactant production. TSB supplemented with colloidal chitin was selected for the experiments.

The use of biosurfactants from microorganisms is a potentially effective pest management strategy. In order to detect biosurfactant production by L193, the oil displacement test, drop-collapsing test and the emulsification index of the cell-free supernatant of strain L193 grown in TSB medium supplemented with colloidal chitin were used. The pattern observed was also found with respect to other biosurfactants produced by microorganisms (Lee et al., 2008).

The efficiency of biosurfactants extracted from strain L193 was evaluated by measuring the critical micelle concentration (CMC) as well as emulsification and oil spreading (displacement) activity. CMC values for the different biosurfactants tested range from $9 \mathrm{mg} / \mathrm{L}$ (Sivapathasekaran et al., 2009) to $140 \mathrm{mg} / \mathrm{L}$ (Mukherjee and Das, 2005). The low CMC value (9.38 $\mathrm{mg} / \mathrm{L})$ for $\mathrm{L} 193$ 


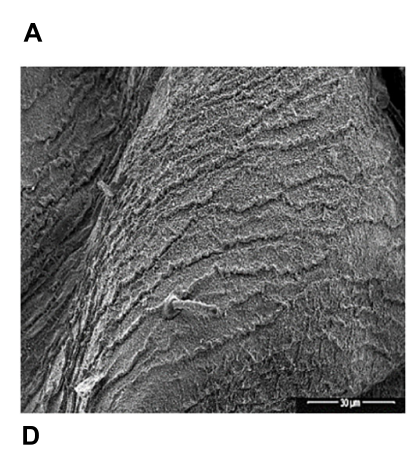

B C
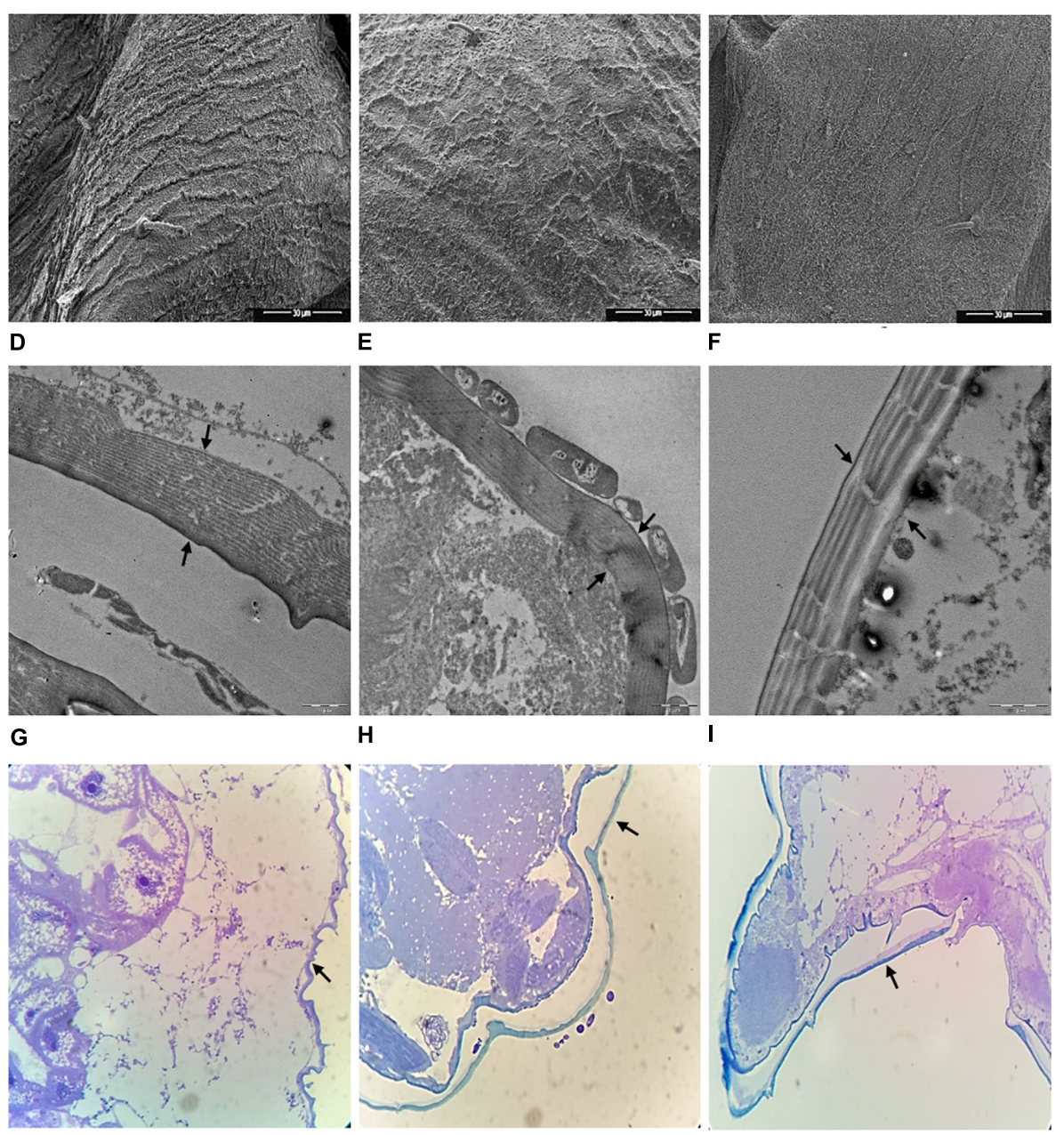

FIGURE 6 | Micrographs of aphid thoraxes produced by scanning electron microscopy (A-C), transmission electron microscopy (D-F) and optical microscopy (G-I) of aphids treated only with TSB medium (A, D, and G), the L193 culture (B, E, and $\mathbf{H}$ ) and the biosurfactant produced by L193 (C, F, and I). Arrows indicate aphid membranes.

indicates that this biosurfactant is more efficient than other biological surfactants (Sriram et al., 2011).

The oil spreading test and the emulsification indices used for the surfactant produced by L193 showed results very similar to those for positive controls such as Triton X-100. These properties of L193 lipopeptides, together with their CMC, highlight their potential biotechnological, biomedical and environmental applications due to their ability to reduce interfacial tension between aqueous and oleous mixtures.

In this study, we also analysed the production of glucosidase enzymes (amylase and chitinase) and proteases (caseinase) by strain L193 in order to determine its potential insecticidal capacity, as the insect cuticle is composed mainly of chitin nanofibres embedded in a matrix of proteins, polyphenols and water with small amounts of lipid. Chitin is also a common constituent of insect exoskeletons which support the epidermal cuticles and the peritrophic matrices lining the gut epithelium (Merzendorfer and Zimoch, 2003).
The role of such lytic enzymes in the insecticidal activity of this strain has previously been observed in the genus Bacillus (Driss et al., 2011). The undiluted L193 culture supernatants on $1 \%(\mathrm{w} / \mathrm{v})$ chitin-containing media displayed enhanced chitinase, amylase and caseinase production. Driss et al. (2011) have highlighted the important role played by the chitinase enzyme in $B$. thuringiensis whose integration into ICPs enhanced their insecticidal activity. The synergistic effect of proteases and chitinases on the cuticle degradation mechanism has also been demonstrated (Leger et al., 1986). Moreover, our study demonstrates that L193 produces glucosidases and proteases, thus confirming the insecticidal potential of these enzymes.

Different Bacillus sp., which produce lipopeptides with surfactant properties, have been described (Raaijmakers et al., 2010). These metabolites are regarded as the most common class of compounds produced by Bacillus sp. (Stachelhaus and Marahiel, 2002). The antifungal activity of lipopeptides isolated from B. atrophaeus has also been described 
(Huang et al., 2015). Genomic analysis carried out in our study indicates that $B$. atrophaeus L193 contains non-ribosomal lipopeptide synthetase gene clusters, which include genes involved in producing fengycin, surfactin, bacillomycin and iturin genes.

Aleti et al. (2016) have reported that the lipopeptides fengycins, iturins and surfactins produced by $B$. atrophaeus 176 display antifungal activity and can protect different crops against Rhizoctonia solani infection. However, very few of these compounds produced by Bacillus spp. have been reported to be involved in aphid control, and their insecticidal activity against this insect has not been studied to any significant extent.

The metabolites produced by L193 were identified using electrospray quadrupole time-of-flight mass spectrometry (QTOFS MS), which show that strain L193 can produce four types of lipopeptides: surfactins, bacillomycin $\mathrm{F}$, iturin $\mathrm{A}$, and fengycin B. All these lipopeptides have been previously observed by PCR. Although some studies have described the control of plant pathogens by surfactins (Chen et al., 2013), little research has been carried out on the aphicidal activity of these molecules produced by the genus Bacillus. To our knowledge, only two studies have analysed the role of surfactins produced by different Bacillus sp. acting as aphicidal metabolites (Yun et al., 2013; Yang et al., 2017), while the aphicidal role played by other lipopeptides, such as iturin, bacillomycin and fengycin, remains unclear.

In vivo studies of barley plants infested with three $3^{\text {rd }}$-instar $R$. padi aphids and treated with B. atrophaeus L193. The results show high levels of activity against $R$. padi for all of the treatments tested, L193 culture, cell-free supernatant and biosurfactant.

The highest mortality rate was observed after $24 \mathrm{~h}$ of incubation. As indicated above, the predominant metabolites present in the biosurfactant produced by strain L193 were lipopeptides, whose insecticidal activity against $R$. padi was also demonstrated. The mechanisms involved in the anti-aphid activity of lipopeptides produced by the genus Bacillus sp. remain unclear. Yun et al. (2013) identified a surfactin acting as an aphicidal metabolite produced by B. amyloliquefaciens G1. More recently, Yang et al. (2017) showed that $B$. subtilis Y9 produces biosurfactants which act as insecticidal metabolites against this aphid species. Both studies investigated aphid mortality rates using a topic assay method similar to that used in our study. However, most studies report that the anti-aphid insecticidal activity of the genus $B$. thuringiensis involves ingestion (Bravo et al., 2007).

Aphid feeding was evaluated by measuring the amount of honeydew excreted by the whole aphid population. The samples of L193 culture, cell-free supernatant and surfactant treatments showed a reduction in the honeydew excreted as compared to controls. These results indicate that L193 topic treatments not only affected cuticle integrity but also aphid feeding capacity. Similar results were found in a study of Bacillus velezensis YC7010 as an inductor of systemic anti-aphid resistance by plants (Rashid et al., 2017), although, in this case, the treatment was by ingestion.

Microscopy data on aphids treated with the L193 culture or the biosurfactant produced by L193 are given in this study. Scanning electron microscopy (SEM) analysis shows clear evidence of damage to the cuticle in aphids treated with L193 culture and the biosurfactant. Transmission electron microscopy
(TEM) and optical microscopy confirmed that treatment with L193 affects the cuticular membrane. With regard to treatment with the biosurfactant, a clear change in cuticle structure was also observed. Lipopeptides appear to induce aphid cuticle dehydration due to interaction with cuticle molecules such as phospholipids and fatty acids (Puterka et al., 2003; Jang et al., 2013). We hypothesise that the biosurfactant produced by L193 affects cuticle lipids and leads to membrane perturbation. This mechanism is corroborated by microscopy observations which showed that the treatment tested in this study causes clear changes in the endocuticle layer of aphids. Similar results have been reported for other biosurfactants, such as rhamnolipids, produced by different species of Pseudomonas sp. (Kim et al., 2011; Jang et al., 2013).

Bacillus atrophaeus L193 produces a biosurfactant with enhanced physicochemical properties as compared to other biological surfactants described to date. In addition, genomic analysis indicated that L193 contains gene clusters for the biosynthesis of non-ribosomal lipopeptide synthetases. This was confirmed by Q-TOF MS, which detected the presence of different types of lipopeptides in the biosurfactant. The in vivo studies carried out suggest that the biosurfactants produced by B. atrophaeus L193 may be useful for controlling aphids. To the best of our knowledge, this is the first study to confirm the insecticidal activity of $B$. atrophaeus against $R$. padi, one of the most abundant and economically important aphids affecting both winter and spring wheat crops.

\section{AUTHOR CONTRIBUTIONS}

MR assisted with experimental techniques and statistical analysis. $\mathrm{AM}$ and MT assisted with experimental techniques related to previous screening and taxonomic identification. VB assisted with analysing the results and critical revision of the manuscript. MC designed the insecticidal assay, assisted with analysing the results, and critical revision of the manuscript. IS designed the experimental techniques, analysed the results, and drafted the manuscript.

\section{ACKNOWLEDGMENTS}

IS wishes to thank MINECO for her Ramón y Cajal contract. The authors also wish to thank Michael O'Shea for proofreading the English version of this manuscript, José Antonio Siles Martos for the statistical analysis, Encarnación Jurado Alameda for surface tension determination, and Maria Luisa Fernández for the technical support with regard to in vivo analyses.

\section{SUPPLEMENTARY MATERIAL}

The Supplementary Material for this article can be found online at: https://www.frontiersin.org/articles/10.3389/fmicb.2018. 03114/full\#supplementary-material 


\section{REFERENCES}

Abbott, W. S. (1925). A method of computing the effectiveness of a insecticide. J. Econ. Entomol. 18, 265-267. doi: 10.1093/jee/18.2.265a

Aleti, G., Lehner, S., Bacher, M., Compant, S., Nikolic, B., Plesko, M., et al. (2016). Surfactin variants mediate species-specific biofilm formation and root colonization in Bacillus. Environ. Microbiol. 18, 2634-2645. doi: 10.1111/14622920.13405

Altschul, S. F., Gish, W., Miller, W., Myers, E. W., and Lipman, D. J. (1990). Basic local alignment search tool. J. Mol. Biol. 215, 403-410. doi: 10.1016/S00222836(05)80360-2

Barrow, G., and Feltham, R. (1993). Cowan and Steel's Manual for the Identification of Medical Bacteria, 3rd Edn. Cambridge: Cambridge University Press, doi: 10.1111/j.2042-7158.1965.tb07589.x

Biswas, S. C., Dubreil, L., and Marion, D. (2001). Interfacial behavior of wheat puroindolines: study of adsorption at the air-water interface from surface tension measurement using wilhelmy plate method. J. Colloid Interface Sci. 244, 245-253. doi: 10.10006/jcis.2001.7940

Biurrun, R., Lezáun, J. A., Zúniga, J., Garnica, I., and Llorens, M. (2010). Virus del enanismo amarillo de la cebada (BYDV). Navarra Agrar. 183, 24-28.

Bravo, A., Gill, S. S., and Soberon, M. (2007). Mode of action of Bacillus thuringiensis cry and cyt toxins and their potential for insect control. Toxicon 49, 423-435. doi: 10.1016/j.toxicon.2006.11.022

Chen, Y., Yan, F., Chai, Y., Liu, H., Kolter, R., Losick, R., et al. (2013). Biocontrol of tomato wilt disease by Bacillus subtilis isolates from natural environments depends on conserved genes mediating biofilm formation. Environ. Microbiol. 15, 848-864. doi: 10.1111/j.1462-2920.2012.02860.x

Chung, S., Kong, H., Buyer, J. S., Lakshman, D. K., Lydon, J., Kim, S. D., et al. (2008). Isolation and partial characterization of Bacillus subtilis ME488 for suppression of soilborne pathogens of cucumber and pepper. Appl. Microbiol. Biotechnol. 80, 115-123. doi: 10.1007/s00253-008-1520-4

Cooper, D. G., and Goldenberg, B. G. (1987). Surface-active agents from two Bacillus species. Appl. Environ. Microbiol. 53, 224-229.

Cooper, D. G., Macdonald, C. R., Duff, S. J., and Kosaric, N. (1981). Enhanced production of surfactin from Bacillus subtilis by continuous product removal and metal cation additions. Appl. Environ. Microbiol. 42, $408-412$.

Copping, L. G. (2004). The Manual of Biocontrol Agents. Alton: British Crop Protection Council.

Dhami, M. K., Weir, B. S., Taylor, M. W., and Beggs, J. R. (2013). Diverse honeydew-consuming fungal communities associated with scale insects. PLoS One 8:e70316. doi: 10.1371/journal.pone.0070316

Driss, F., Rouis, S., Azzouz, H., Tounsi, S., Zouari, N., and Jaoua, S. (2011). Integration of a recombinant chitinase into Bacillus thuringiensis parasporal insecticidal crystal. Curr. Microbiol. 62, 281-288. doi: 10.1007/s00284-0109704-4

Dutton, A., Romeis, J., and Bigler, F. (2003). Assessing the risks of insect resistant transgenic plants on entomophagous arthropods Bt-maize expressing Cryl Ab as a case study. BioControl 48, 611-636. doi: 10.1023/A:1026313719424

Huang, X. F., Zhou, D., Guo, J., Manter, D. K., Reardon, K. F., and Vivanco, J. M. (2015). Bacillus spp. from rainforest soil promote plant growth under limited nitrogen conditions. J. Appl. Microbiol. 118, 672-684. doi: 10.1111/jam.12720

Jang, J. Y., Yang, S. Y., Kim, Y. C., Lee, C. W., Park, M. S., Kim, J. C., et al. (2013). Identification of orfamide A as an insecticidal metabolite produced by Pseudomonas protegens F6. J. Agric. Food Chem. 61, 6786-6791. doi: 10.1021/ jf401218w

Kim, J. H., and Jander, G. (2007). Myzus persicae (green peach aphid) feeding on Arabidopsis induces the formation of a deterrent indole glucosinolate. Plant $\mathrm{J}$. 49, 1008-1019. doi: 10.1111/j.1365-313X.2006.03019.x

Kim, S. K., Kim, Y. C., Lee, S., Kim, J. C., Yun, M. Y., and Kim, I. S. (2011). Insecticidal activity of rhamnolipid isolated from Pseudomonas sp. EP-3 against green peach aphid (Myzus persicae). J. Agric. Food Chem. 59, 934-938. doi: $10.1021 / \mathrm{jf} 104027 \mathrm{x}$

Lane, D. J. (1991). "16S/23S rRNA sequencing," in Nucleic Acid Techniques in Bacterial Systematics, eds E. Stackebrandt and M. Goodfellow (Chichester: John Wiley and Sons), 115-175.

Lee, S. C., Lee, S. J., Kim, S. H., Park, I. H., Lee, Y. S., Chung, S. Y., et al. (2008). Characterization of new biosurfactant produced by Klebsiella sp. Y6-1 isolated from waste soybean oil. Bioresour. Technol. 99, 2288-2292. doi: 10. 1016/j.biortech.2007.05.020

Leger, R. J. S., Charnley, A. K., and Cooper, R. M. (1986). Cuticle-degrading enzymes of entomopathogenic fungi: synthesis in culture on cuticle. J. Invertebr. Pathol. 48, 85-95. doi: 10.1016/0022-2011(86)90146-1

Leroy, P. D., Sabri, A., Heuskin, S., Thonart, P., Lognay, G., Verheggen, F. J., et al. (2011). Microorganisms from aphid honeydew attract and enhance the efficacy of natural enemies. Nat. Commun. 2:348. doi: 10.1038/ncomms 1347

Liu, X. F., Hu, X. S., Keller, M. A., Zhao, H. Y., Wu, Y. F., and Liu, T. X. (2014). Tripartite interactions of barley yellow dwarf virus, Sitobion avenae and wheat varieties. PLoS One 9:e106639. doi: 10.1371/journal.pone.0106639

Merzendorfer, H., and Zimoch, L. (2003). Chitin metabolism in insects: structure, function and regulation of chitin synthases and chitinases. J. Exp. Biol. 206, 4393-4412. doi: 10.1242/jeb.00709

Mora, I., Cabrefiga, J., and Montesinos, E. (2011). Antimicrobial peptide genes in Bacillus strains from plant environments. Int. Microbiol. 14, 213-223. doi: $10.2436 / 20.1501 .01 .151$

Morikawa, M., Hirata, Y., and Imanaka, T. (2000). A study on the structurefunction relationship of lipopeptide biosurfactants. Biochim. Biophys. Acta 1488, 211-218. doi: 10.1016/S1388-1981(00)00124-4

Mukherjee, A. K., and Das, K. (2005). Correlation between diverse cyclic lipopeptides production and regulation of growth and substrate utilization by Bacillus subtilis strains in a particular habitat. FEMS Microbiol. Ecol. 54, 479-489. doi: 10.1016/j.femsec.2005.06.003

Nisbet, A. J., Woodford, J. A. T., and Strang, R. H. C. (1994). Quantifying aphid feeding on non-radioactive food sources. Entomol. Exp. Appl. 72, 85-89. doi: 10.1111/j.1570-7458.1994.tb01805.x

Palma, L., Munoz, D., Berry, C., Murillo, J., de Escudero, I. R., and Caballero, P. (2014). Molecular and insecticidal characterization of a novel cry-related protein from Bacillus thuringiensis toxic against Myzus persicae. Toxins 6, 3144-3156. doi: 10.3390/toxins6113144

Phale, P. S., Savithri, H. S., Rao, N. A., and Vaidyanathan, C. S. (1995). Production of biosurfactant "Biosur-Pm" by Pseudomonas maltophila CSv 89. Characterization and role in hydrocarbon uptake. Arch. Microbiol. 163, 424-431. doi: 10.1007/BF00272131

Porcar, M., Grenier, A. M., Federici, B., and Rahbe, Y. (2009). Effects of Bacillus thuringiensis delta-endotoxins on the pea aphid (Acyrthosiphon pisum). Appl. Environ. Microbiol. 75, 4897-4900. doi: 10.1128/AEM.00686-09

Puterka, G. J., Farone, W., Palmer, T., and Barrington, A. (2003). Structurefunction relationships affecting the insecticidal and miticidal activity of sugar esters. J. Econ. Entomol. 96, 636-644. doi: 10.1603/0022-0493-96. 3.636

Raaijmakers, J. M., De Bruijn, I., Nybroe, O., and Ongena, M. (2010). Natural functions of lipopeptides from Bacillus and Pseudomonas: more than surfactants and antibiotics. FEMS Microbiol. Rev. 34, 1037-1062. doi: 10.1111/ j.1574-6976.2010.00221.x

Rashid, M. H., Khan, A., Hossain, M. T., and Chung, Y. R. (2017). Induction of systemic resistance against aphids by endophytic Bacillus velezensis YC7010 via expressing phytoalexin deficient4 in arabidopsis. Front. Plant Sci. 8:211. doi: 10.3389/fpls.2017.00211

Sanahuja, G., Banakar, R., Twyman, R. M., Capell, T., and Christou, P. (2011). Bacillus thuringiensis: a century of research, development and commercial applications. Plant biotechnol. J. 9, 283-300. doi: 10.1111/j.1467-7652.2011. 00595.x

Sivapathasekaran, C., Mukherjee, S., Samanta, R., and Sen, R. (2009). Highperformance liquid chromatography purification of biosurfactant isoforms produced by a marine bacterium. Anal. Bioanal. Chem. 395, 845-854. doi: 10.1007/s00216-009-3023-2

Song, B., Rong, Y. J., Zhao, M. X., and Chi, Z. M. (2013). Antifungal activity of the lipopeptides produced by Bacillus amyloliquefaciens anti-CA against Candida albicans isolated from clinic. Appl. Microbiol. Biotechnol. 97, 7141-7150. doi: $10.1007 / \mathrm{s} 00253-013-5000-0$

Sriram, M. I., Gayathiri, S., Gnanaselvi, U., Jenifer, P. S., Raj, S. M., and Gurunathan, S. (2011). Novel lipopeptide biosurfactant produced by hydrocarbon degrading and heavy metal tolerant bacterium Escherichia fergusonii KLU01 as a potential tool for bioremediation. Bioresour. Technol. 102, 9291-9295. doi: 10.1016/j.biortech.2011.06.094 
Stachelhaus, T. M. H., and Marahiel, M. A. (2002). "Nonribosomal assembly of peptide antibiotics on modular protein templates," in Bacillus Subtilis and its Closest Relatives-From Genes to Cells, eds A. L. Sonenshein, J. A. Hoch, and R. M. Losick (Washington, DC: ASM Press), 415-435. doi: 10.1128/ 9781555817992.ch30

Tapi, A., Chollet-Imbert, M., Scherens, B., and Jacques, P. (2010). New approach for the detection of non-ribosomal peptide synthetase genes in Bacillus strains by polymerase chain reaction. Appl. Microbiol. Biotechnol. 85, 1521-1531. doi: 10.1007/s00253-009-2176-4

Torres-Quintero, M. C., Peña-Chora, G., Hernández-Velázquez, V. M., and Arenas-Sosa, I. (2015). Signs of Bacillus thuringiensis (Bacillales: Bacillaceae) infection in Myzus persicae (Hemiptera: Aphididae): koch's postulates. Fla. Entomol. 98, 799-802. doi: 10.1653/024.098.0264

Wu, Y. J., Cheng, C. Y., and Li, Y. K. (2009). Cloning and expression of chitinase a from Serratia marcescens for large-scale preparation of N,N -Diacetyl chitobiose. J. Chin. Chem. Soc. 56, 688-695. doi: 10.1002/jccs.200900103

Yang, S. Y., Lim, D. J., Noh, M. Y., Kim, J. C., Kim, Y. C., and Kim, I. S. (2017). Characterization of biosurfactants as insecticidal metabolites produced by Bacillus subtilis Y9. Entomol. Res. 47, 55-59. doi: 10.1111/1748-5967. 12200

Yoon, S. H., Ha, S. M., Kwon, S., Lim, J., Kim, Y., Seo, H., et al. (2017). Introducing EzBioCloud: a taxonomically united database of $16 \mathrm{~S}$ rRNA and whole genome assemblies. Int. J. Syst. Evol. Microbiol. 67, 1613-1617. doi: 10.1099/ijsem.0. 001755

Youssef, N. H., Duncan, K. E., Nagle, D. P., Savage, K. N., Knapp, R. M., and McInerney, M. J. (2004). Comparison of methods to detect biosurfactant production by diverse microorganisms. J. Microbiol. Methods 56, 339-347. doi: 10.1016/j.mimet.2003.11.001

Yun, D. C., Yang, S. Y., Kim, Y. C., Kim, I. S., and Kim, Y. H. (2013). Identification of surfactin as an aphicidal metabolite produced by Bacillus amyloliquefaciens G1. J. Korean Soc. Appl. Biol. Chem. 56, 751-753. doi: 10.1007/s13765-0133238-y

Conflict of Interest Statement: The authors declare that the research was conducted in the absence of any commercial or financial relationships that could be construed as a potential conflict of interest.

Copyright (c) 2018 Rodríguez, Marín, Torres, Béjar, Campos and Sampedro. This is an open-access article distributed under the terms of the Creative Commons Attribution License (CC BY). The use, distribution or reproduction in other forums is permitted, provided the original author(s) and the copyright owner(s) are credited and that the original publication in this journal is cited, in accordance with accepted academic practice. No use, distribution or reproduction is permitted which does not comply with these terms. 